\title{
PENGARUH BENTUK MODEL VIRTUAL REALITY TERHADAP LAMA DURASI PENGGUNAAN DAN AKTIVITAS PENGGUNA
}

\author{
1) Ichsan Mardani, ${ }^{2)}$ Rio Wirawan. S. Kom. MMSI \\ Mardani300@gmail.com, Rio.myself@gmail.com \\ 1) Teknik Informatika, ${ }^{2)}$ Sistem Informasi, Fakultas Ilmu Komputer \\ Universitas Pembangunan Nasional Veteran Jakarta \\ Jalan RS Fatmawati Pondok Labu Jakarta Selatan, Jawa Barat 12450
}

\begin{abstract}
Abstrak
Dengan pesatnya perkembangan komputer dan teknologi, virtual reality merupakan salah satu terobosan yang dapat diambil contoh dalam kombinasi antara computer serta perkembangan teknologi. Penerapan virtual reality sangat banyak digunakan untuk permainan (game) dan hiburan. Beberapa model virtual reality menjadi salah satu pilihan untuk memilih dalam menggunakan virtual reality sebagai kegiatan dengan teknologi. Model dan bentuk yang di sajikan memiliki variasi dan keunggulan di berbagai macam kegiatan yang dapat dilakukan dengan virtual reality, akan tetapi, virtual reality belum menjadi pilihan utama. Hal ini disebabkan kurangnya pemahaman dengan bentuk model mana yang baik digunakan dengan kegiatan apa yang dilakukan dengan virtual reality. Kenyamanan dalam menggunakan virtual reality menjadi perhatian beberapa vendor untuk berinovasi guna memilih bentuk yang dapat memberikan kenyamanan terhadap pengguna dari virtual reality.
\end{abstract}

Kata kunci virtual reality, model virtual reality

\section{PENDAHULUAN}

Perubahan antarmuka antara user dengan komputer menjadi perhatian khusus dalam virtual reality. Banyaknya media / aplikasi yang disajikan secara 3D menjadi pusat perhatian user menggunakan virtual reality. Aplikasi yang dapat digunakan untuk virtual reality ada berbagai macam, contohnya penggunaan Virtual reality dalam video dan bermain (game). Dalam hal ini kenyamanan dan beraktivitas dengan menggunakan virtual reality menjadi perhatian khusus dalam perkembangan virtual reality.

Kurangnya pemahaman dan kenyamanan dalam virtual reality menjadi salah satu faktor utama dalam memilih virtual reality sebagai antarmuka dengan aplikasi. Disamping itu kenyaman penggunaan virtual reality juga menjadi perhatian dalam penggunaan virtual reality. Beberapa bentuk dan model dari virtual reality itu sendiri menjadi pembahasan yang menarik dalam mendesin alat virtual reality. Meskipun virtual reality telah menjadi media atarmuka yang menarik, kenyamanan terhadap penggunaan virtual reality belum dapat disajikan secara optimal.

Tujuan dari penelitian ini adalah memberikan gambaran tentang model atau bentuk dari virtual reality yang dapat memberikan kenyamanan dalam menggunakan virtual reality. Target luaran dari penelitian ini, diharapkan dapat memberikan gambaran model dari virtual reality dengan memberikan model mana yang memberikan kenyamanan dalam berinterkasi dengan menggunakan virtual reality. 


\section{LANDASAN TEORI}

$\begin{array}{lcr}\text { Virtual } & \text { reality } & \text { mulai } \\ \text { dipersembahakan } & \text { pada tahun } & 1990 \mathrm{~s}, \\ \text { Manufactur } & \text { mobil } & \text { Ford }\end{array}$ mempersembahkan virtual reality sebagai desain dan produksi kendaraan di tahun 1999 (Gaudiosi 2015).

Namun virtual reality tidak pernah menjadi pusat perhatian konsumen. Dampak VR pada game, hiburan, pemasaran, pendidikan, desain produk, menjadi pusat perhatian saat ini. pengembangan virtual reality sekarang sedang di perhatikan, di karenakan perkembangan dari virtual reality sudah hamper sama dengan berkembanganya social media pada tahun 2008 (Morris 2016).

Menurut Oxford English Dictionary, virtual reality mengacu pada "simulasi generasi komputer dari gambar tiga dimensi atau lingkungan yang dapat berinteraksi dengan cara yang tampaknya nyata atau fisik oleh orang yang menggunakan peralatan elektronik khusus, seperti helm dengan layar di dalam atau sarung tangan dilengkapi dengan sensor." NASA (2016) bahkan memberikan definisi yang lebih teknis, "penggunaan teknologi komputer untuk membuat efek dari interaktif dunia tiga dimensi di mana benda memiliki rasa kehadiran spasial.

Karakteristik kunci dari pengalaman virtual reality adalah perasaan dari 'presence' (kehadiran)pengguna merasa seperti mereka benarbenar di lingkungan sintetis yang disajikan." Salah satu teknologi yang berhubungan virtual reality adalah , augmented reality (AR), melibatkan overlay benda digital dan informasi di dunia nyata melalui perangkat digital (seperti Google Glass atau smartphone). Contoh terbaru adalah populer ponsel game mobile Pokemon Go. Demikian pula, realitas campuran (Mixed Reality), menggabungkan real-time konten software dunia 3D dengan dunia nyata, contoh terkenal menjadi platform yang HoloLens MR Microsoft.

Bisnis investasi di virtual reality menjadi pusat perhatian utama dalam beberapa tahun terakhir. Facebook menghabiskan \$2 miliar pada Oculus Rift Maret 2014. Google menghabiskan \$ 542.000 .000 tentang Magic Leap pada bulan Oktober 2014. Dari Q1 2014 Q2 2015, lebih dari $\$ 1$ miliar telah diinvestasikan di 91 penawaran di VR dan AR (EMarketer 2016). Lebih dari teknologi, konten adalah kunci keberhasilan dari VR. Menurut Goldman Sachs, pasar konten VR bermerek bisa bernilai \$ 80 miliar pada 2025 (Bellini 2016).

\section{METODE PENELITIAN}

Berikut flowchart rancangan penelitian untuk Pengaruh bentuk model virtual reality terhadap lama durasi penggunaan dan aktivitas pengguna :

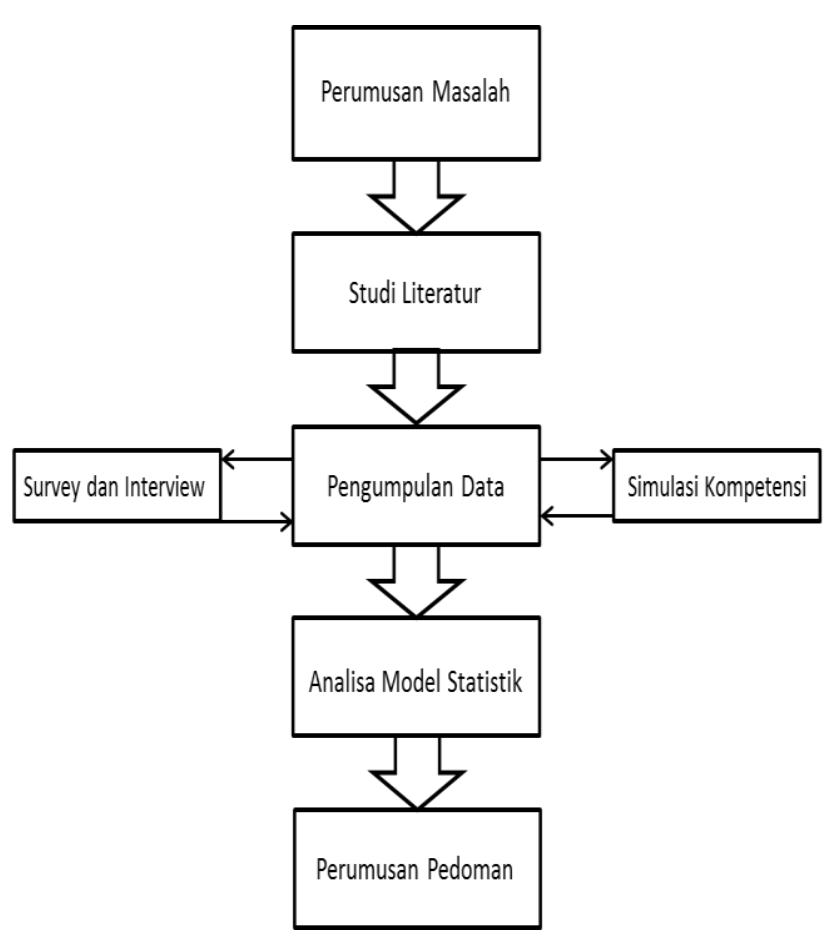

Gambar 1 : Flowchar Diagram 
Tahapan perancangan sistim pada gambar 1 di jabarkan menjadi 5 tahapan :

1. Perumusan Masalah

Tahapan ini menjabarkan digunakan untuk menjelaskan masalah atau isu yang ada pada penggunaan virtual reality.

2. Studi literature

Mempelajari penggunaan dan implementasi dari virtual reality beserta perkembangan, implementasi pada objek

3. Pengumpulan data

Dalam pengumpulan data, tahapan ini memberikan user / pengguna menggunakan secara langsung virtual rality. Adapun target pengguna yang diharapkan mencapai dari 200 orang, dimana tiap peserta mengisi quisoner setelah mencoba alat virtual yang telah disediakan. Virtual reality yang di gunakan ada 2 macam :

a. Playstation Virtual reality

Pengguna mencoba memainkan permaian dari playstation dengan menggunakan Virtual reality sebagai media layar.

b. Vr BOX Android Smart phone Pengguna mencoba berinteraksi dengan virtual rality dengan module yang terdapat dari smartphone. Model ini digunakan 2 jenis yaitu Vrbox cardboard, dan Vb box Android Smart phone.

4. Analisa model statistic

Analisa data kuesioner yang diberikan kepada 150 mahasiswa di universitas pembangunan nasional veteran jakarta. Data statistik tersebut yang dimasud adalah menggunakan uji validitas, uji reabilitas, uji frekuensi, uji korelasi atau uji kelinieranitas tergantung jenis data yang ada.
5. Perumusan Pedoman

Perumusan pedoman diambil dari kesimpulan - kesimpulan butir penelitian. Pedoman diharapkan akan menjadi dasar referensi penggunaan dan pemilihan bentuk model, lama penggunaan, ataupun jenis yang dimainkan, sehinga penggunaan $\mathrm{Vr}$ lebih dapat selektif dan efektif.

\section{HASIL DAN PEMBAHASAN}

Uji Frekuensi

Uji frekuensi dilakukan untuk mengetahui jumlah masing - masing butir, adapun hasil uji frekuensi dilakukan sebagai berikut:

Berdasarkan Jenis kelamin, didapat 107 berjenis kelamin laki - laki , dan ada 43 berjenis kelamin perempuan, dengan total 150 responden. Adapun data lengkap disajikan pada tabel 1 dibawah ini:

Tabel 1. Uji Frekuensi berdasarkan jenis kelamin.
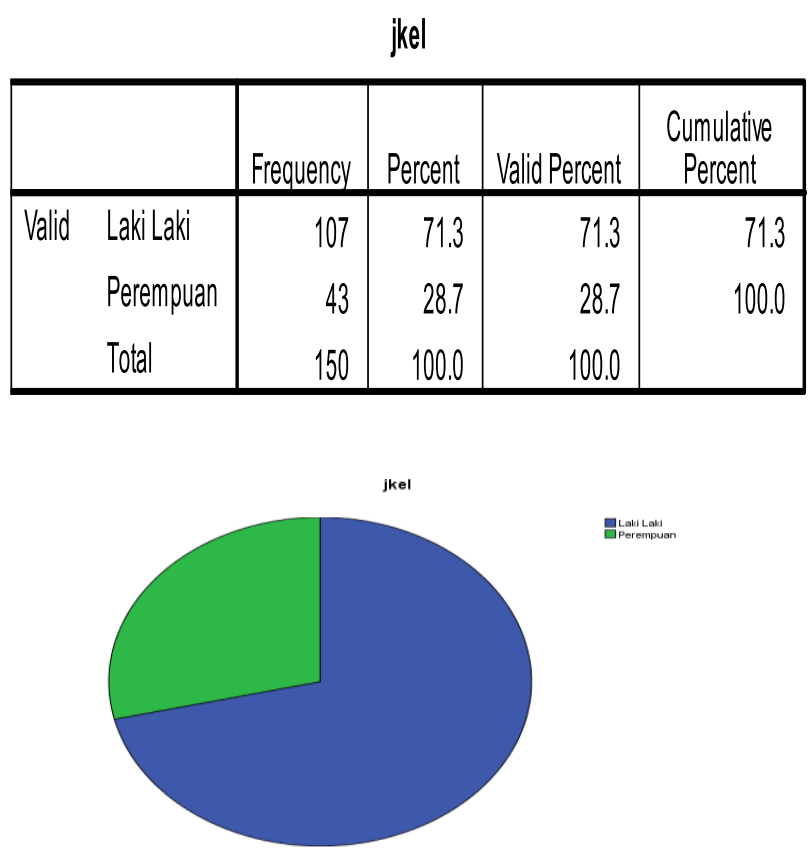

Gambar 2 Diagram PIE Uji Frekuensi berdasarkan jenis kelamin. 
Warna biru pada gambar 2 diatas menampilkan pengguna laki-laki dan hijau perempuan. Uji frekuensi berdasarkan fakultas mahasiswa responden. Adapun data lengkap disajikan pada tabel 2 dibawah ini:

Tabel 2. Uji Frekuensi berdasarkan Fakultas

fakultas

\begin{tabular}{|l|r|r|r|r|}
\hline & Frequency & Percent & Valid Percent & $\begin{array}{c}\text { Cumulative } \\
\text { Percent }\end{array}$ \\
\hline Valid Fisip & 21 & 14.0 & 14.0 & 14.0 \\
FIIK & 108 & 72.0 & 72.0 & 86.0 \\
FEB & 11 & 7.3 & 7.3 & 93.3 \\
FH & 5 & 3.3 & 3.3 & 96.7 \\
Fikes & 4 & 2.7 & 2.7 & 99.3 \\
FT & 1 & .7 & .7 & 100.0 \\
Total & 150 & 100.0 & 100.0 & \\
\hline
\end{tabular}
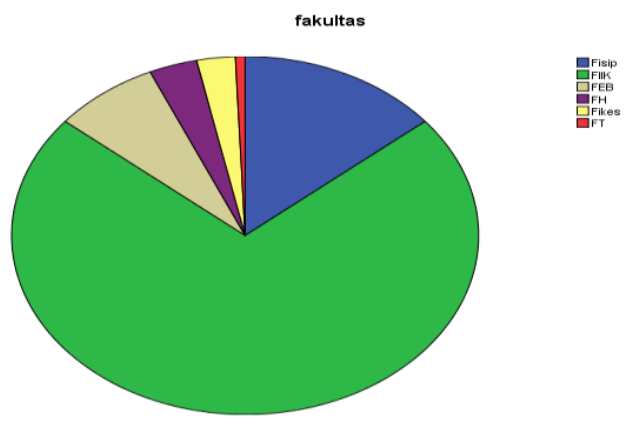

\section{Gambar 3 Diagram PIE Uji Frekuensi berdasarkan fakultas}

Uji frekuensi berdasarkan fakultas mahasiswa responden. Adapun data lengkap disajikan pada tabel 3 dibawah ini:

Tabel 3. Uji Frekuensi berdasarkan Model Vr

\begin{tabular}{|ll|r|r|r|r|}
\multicolumn{7}{|c|}{ rrM } \\
\hline & & & & \multicolumn{1}{c|}{$\begin{array}{c}\text { Cumulative } \\
\text { Percent }\end{array}$} \\
\hline Valid & CardBoard & 15 & 10.0 & 10.0 & 10.0 \\
& Vr Box & 26 & 17.3 & 17.3 & 27.3 \\
& Vr Playstation & 109 & 72.7 & 72.7 & 100.0 \\
& Total & 150 & 100.0 & 100.0 & \\
\hline
\end{tabular}

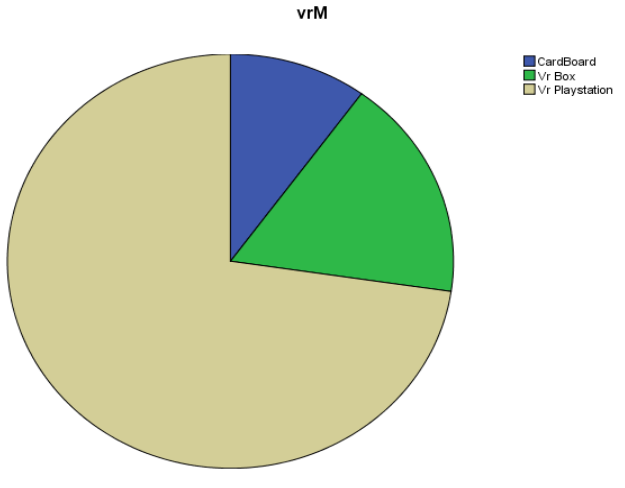

\section{Gambar 4 Diagram PIE Uji Frekuensi berdasarkan model Vr}

Berikut disajikan hasil uji frekuensi dari masing masing butir kuesioner.

Hasil Keseluruhan P1 (Menyatakan Pusing Atau tidaknya dalam menggunakan $\mathrm{Vr}$ )

Tabel 4. Uji Frekuensi P1

\begin{tabular}{|c|c|c|c|c|c|}
\hline & & Frequency & Percent & Valid Percent & $\begin{array}{l}\text { Cumulative } \\
\text { Percent }\end{array}$ \\
\hline \multirow[t]{5}{*}{ Valid } & 1 & 15 & 10.0 & 10.0 & 10.0 \\
\hline & 2 & 58 & 38.7 & 38.7 & 48.7 \\
\hline & 3 & 62 & 41.3 & 41.3 & 90.0 \\
\hline & 4 & 15 & 10.0 & 10.0 & 100.0 \\
\hline & Total & 150 & 100.0 & 100.0 & \\
\hline
\end{tabular}

Dari table uji frekuensi 1(Tabel 4) memberikan informasi $10 \%$ menyatakan sangat setuju dan $41.3 \%$ menyatakan setuju, hal ini berarti $51.5 \%$ menyatakan pusing dalam menggunakan Vr. Sebaliknya $38.7 \%$ menjawab tidak setuju dan $10 \%$ menjawab sangat tidak setuju hal ini berarti $48.7 \%$ menyatakan tidak pusing dalam menggunakan $\mathrm{Vr}$.

Hasil Keseluruhan P2 (Menyatakan sakit mata atau tidaknya dalam menggunakan $\mathrm{Vr})$ 
Tabel 5. Uji Frekuensi P2

\begin{tabular}{|c|c|c|c|c|c|}
\hline & & Frequency & Percent & Valid Percent & $\begin{array}{c}\text { Cumulative } \\
\text { Percent }\end{array}$ \\
\hline \multirow[t]{5}{*}{ Valid } & 1 & 30 & 20.0 & 20.0 & 20.0 \\
\hline & 2 & 82 & 54.7 & 54.7 & 74.7 \\
\hline & 3 & 35 & 23.3 & 23.3 & 98.0 \\
\hline & 4 & 3 & 2.0 & 2.0 & 100.0 \\
\hline & Total & 150 & 100.0 & 100.0 & \\
\hline
\end{tabular}

$2 \%$ menyatakan sangat setuju dan $23.3 \%$ menyatakan setuju, hal ini berarti $25.3 \%$ menyatakan sakit mata dalam menggunakan Vr. Sebaliknya $54.7 \%$ menjawab tidak setuju dan $20 \%$ menjawab sangat tidak setuju hal ini berarti $74.7 \%$ menyatakan tidak sakit mata dalam menggunakan Vr.

Hasil Keseluruhan P3 (Menyatakan menikmati permainan menggunakan $\mathrm{Vr}$ )

Tabel 6. Uji Frekuensi P3

p3

\begin{tabular}{|c|c|c|c|c|c|}
\hline & & Frequency & Percent & Valid Percent & $\begin{array}{l}\text { Cumulative } \\
\text { Percent }\end{array}$ \\
\hline \multirow[t]{5}{*}{ Valid } & 1 & 1 & .7 & .7 & .7 \\
\hline & 2 & 6 & 4.0 & 4.0 & 4.7 \\
\hline & 3 & 61 & 40.7 & 40.7 & 45.3 \\
\hline & 4 & 82 & 54.7 & 54.7 & 100.0 \\
\hline & Total & 150 & 100.0 & 100.0 & \\
\hline
\end{tabular}

$54.7 \%$ menyatakan sangat setuju dan $40.7 \%$ menyatakan setuju, hal ini berarti 95.4\% menyatakan sakit mata dalam menggunakan Vr. Sebaliknya 4\% menjawab tidak setuju dan $0.7 \%$ menjawab sangat tidak setuju hal ini berarti $4.7 \%$ menyatakan tidak sakit mata dalam menggunakan $\mathrm{Vr}$.

Hasil Keseluruhan P4 (Menyatakan dapat memainkan banyak Model Vr)

\section{Tabel 7. Uji Frekuensi P4}

\begin{tabular}{|ll|r|r|r|r|}
\multicolumn{7}{|c|}{$\mathbf{p 4}$} \\
\hline & & Frequency & Percent & Valid Percent & $\begin{array}{c}\text { Cumulative } \\
\text { Percent }\end{array}$ \\
\hline Valid & 1 & 1 & .7 & .7 & .7 \\
& 2 & 21 & 14.0 & 14.0 & 14.7 \\
& 3 & 102 & 68.0 & 68.0 & 82.7 \\
& 4 & 26 & 17.3 & 17.3 & 100.0 \\
& Total & 150 & 100.0 & 100.0 & \\
\hline
\end{tabular}

17.3\% menyatakan sangat setuju dan $68.0 \%$ menyatakan setuju, hal ini berarti 85.3\% menyatakan memainkan banyak model Vr. Sebaliknya 14\% menjawab tidak setuju dan $0.7 \%$ menjawab sangat tidak setuju hal ini berarti $14.7 \%$ menyatakan tidak tidak dapat memainkan banyak model Vr.

Hasil Keseluruhan P5 (Menyatakan kesanggupan lama dalam menggunakan $\mathrm{Vr}$ )

\section{Tabel 8. Uji Frekuensi P5}

\begin{tabular}{|c|c|c|c|c|c|}
\hline & & Frequency & Percent & Valid Percent & $\begin{array}{c}\text { Cumulative } \\
\text { Percent }\end{array}$ \\
\hline \multirow[t]{5}{*}{ Valid } & 1 & 4 & 2.7 & 2.7 & 2.7 \\
\hline & 2 & 62 & 41.3 & 41.3 & 44.0 \\
\hline & 3 & 65 & 43.3 & 43.3 & 87.3 \\
\hline & 4 & 19 & 12.7 & 12.7 & 100.0 \\
\hline & Total & 150 & 100.0 & 100.0 & \\
\hline
\end{tabular}

12.7\% menyatakan sangat setuju dan 43.3\% menyatakan setuju, hal ini berarti $56 \%$ menyatakan kesanggupan lama dalam menggunakan Vr. Sebaliknya 41.3\% menjawab tidak setuju dan $2.7 \%$ menjawab sangat tidak setuju hal ini berarti $44.4 \%$ menyatakan tidak sakit mata dalam menggunakan

Vr.Hasil Keseluruhan P6 (Menyatakan dan berhenti tengah menggunakan $\mathrm{Vr}$ )

\section{Tabel 9. Uji Frekuensi P6}

p6

\begin{tabular}{|c|c|c|c|c|}
\hline & Frequency & Percent & Valid Percent & $\begin{array}{l}\text { Cumulative } \\
\text { Percent }\end{array}$ \\
\hline Valid 1 & 42 & 28.0 & 28.0 & 28.0 \\
\hline 2 & 73 & 48.7 & 48.7 & 76.7 \\
\hline 3 & 29 & 19.3 & 19.3 & 96.0 \\
\hline 4 & 6 & 4.0 & 4.0 & 100.0 \\
\hline Total & 150 & 100.0 & 100.0 & \\
\hline
\end{tabular}


4\% menyatakan sangat setuju dan $19.3 \%$ menyatakan setuju, hal ini berarti $23.3 \%$ menyatakan berhenti dan dalam tengah menggunakan Vr. Sebaliknya $48.7 \%$ menjawab tidak setuju dan $28 \%$ menjawab sangat tidak setuju hal ini berarti $76.7 \%$ menyatakan tidak menghentikan dalam tengah menggunakan Vr.

\section{SIMPULAN DAN SARAN}

\section{KESIMPULAN}

Berdasarkan penelitian ini dihasilkan kesimpulan Dari penggunaan virtual reality diperoleh rasa pusing sebanyak $51.5 \%$ menyatakan pusing saat menggunakan virtual reality. Namun ada juga reponden sebanyak $25.3 \%$ menyatakan sakit mata saat menggunakan virtual reality. Meskipun begitu ada sebanyak $85.3 \%$ menyatakan dapat memainkan banyak model $\mathrm{Vr}$

\section{SARAN}

Penelitian penggunaan virtual reality ini dirasakan masih memerlukan penelitian lebih lanjut, misalkan adanya responden yang menggunakan kacamata apakah dapat mempengaruhi penggunaan virtual reality, ataupun adanya variabel variabel lainnya yang diduga dikemudain hari dapat mempengaruhi penggunaan virtual reality.

\section{DAFTAR PUSTAKA}

Beeli, G., Casutt, G., Baumgartner, T., \& Jäncke, L. (2008). Modulating presence and impulsiveness by external stimulation of the brain Behavioral and Brain Functions. 4, 33.

Bellini, H. (2016). Profiles in Innovation: The Real Deal with Virtual and Augmented Reality. Available from: http://www.goldmansachs.com/our- thinking/pages/virtual-andaugmentedreality.html

Biocca, F. A., Harms, C., \& Gregg, J. (2001). The Networked Minds measure of social presence: Pilot test of the factor structure and concurrent validity. Proceedings of the 4th Annual International Workshop on Presence, Philadelphia, Pennsylvania. May 21-23.

Bitner, M. J. (1992). Servicescapes: The impact of physical surroundings on customers and employees. Journal of Marketing. 56(2), 57-71.

Blohm, I., \& Leimeister, J. M. (2013), Gamification. Business and Information Systems Engineering.5(4), 275-278.

Brooks, J. (2015). Virtual Reality: Advancing Marketing Research ... and Visualizing a Better World. Los Angeles: Lieberman Research Worldwide.

Chi, H.-H. (2011). Interactive digital advertising vs. virtual brand community: Exploratory study of user motivation and social media marketing responses in Taiwan. Journal of Interactive Advertising. Vol 12 No 1 (Fall 2011), 44-61.

Chu, S.-C., \& Kim, Y. (2011). Determinants of consumer engagement in electronic wordofmouth(eWOM) in social networking sites. International Journal of Advertising, 30 (1). 4775.

eMarketer (2016). Virtual Reality Is an Immersive Medium for Marketers: Marketers should start experimenting sooner rather than later. Available from: http://www.emarketer.com/Article/ Virtual-Reality-Immersive-Medium Marketers/1013526 
Keng, C. J., Chang, W. H., Chen, C. H., \& Chang, Y. Y. (2016). Mere virtual presence with product experience affects brand attitude and purchase intention. Social Behavior and Personality. 44(3), 431.

Kober, S.E., \& Neuper, C. (2013). Personality and presence in virtual reality: Does their relationship depend on the used presence measure? International Journal of Human- Computer Interaction.29(1), 13-25.

Morris, C. (2016). Virtual reality and the new sales experience. Available from:

http://www.campaignlive.com/artic le/virtual-reality-new-salesexperience/1392253

NASA (2016). Virtual Reality: Definition and Requirements. Available from: http://www.nas.nasa.gov/Software/ VWT/vr.html

VRS (2016). History of Virtual Reality. Available from: http://www.vrs.org.uk/virtualreality I history.html. The Computer Journal, 47(4), 448-460. 